Adult longevity and economic take-off : from Malthus to Ben-Porath

D. de la Croix

Discussion Paper 2008-31

Département des Sciences Économiques de l'Université catholique de Louvain 


\title{
Adult Longevity and Economic Take-off: from Malthus to Ben-Porath
}

\author{
David de la Croix \\ Department of Economics and CORE, Université catholique de Louvain
}

November 4, 2008

\begin{abstract}
We propose four arguments favoring the idea that medical effectiveness, adult longevity and height started to increase in Europe before the industrial revolution. This may have prompted households to increase their investment in human skills as a response to longer lives and initiated the transition from stagnation to growth.

JEL Classification Numbers: J11, I12, N30, I20, J24.

Keywords: Life Expectancy, Height, Industrial Revolution, Human Capital, Adult Mortality.
\end{abstract}

\footnotetext{
${ }^{1}$ I acknowledge the financial support of the Belgian French speaking community (Grant ARC 03/08235 "New Macroeconomic Approaches to the Development Problem") and the Belgian Federal Government (Grant PAI P6/07 "Economic Policy and Finance in the Global Economy: Equilibrium Analysis and Social Evaluation").
} 


\section{Introduction}

Adult longevity, as measured for example by the conditional life expectancy at age 10, is undoubtedly positively correlated with income per person. This is true both over time and across countries. Figure 1 plots this relationship for Sweden from 1751 until today. The dotted line represents life expectancy at age 10 and is measured in years on the right axis, ${ }^{1}$ while the solid line represents the logarithm of income per capita in constant dollars and is measured on the left axis. ${ }^{2}$ The trends in the two series are amazingly similar. Up to the 1820 s we have stagnation in both series, then a slight upward trend after the Napoleonic wars is discernible, but at a very modest level (averaging around half a percent a year for income per capita). There is an increasing growth trend though and, after 1850, average growth rates in income per capita start to exceed the 1 percent level.

Figure 1: Life expectancy at age 10 and income per capita in Sweden

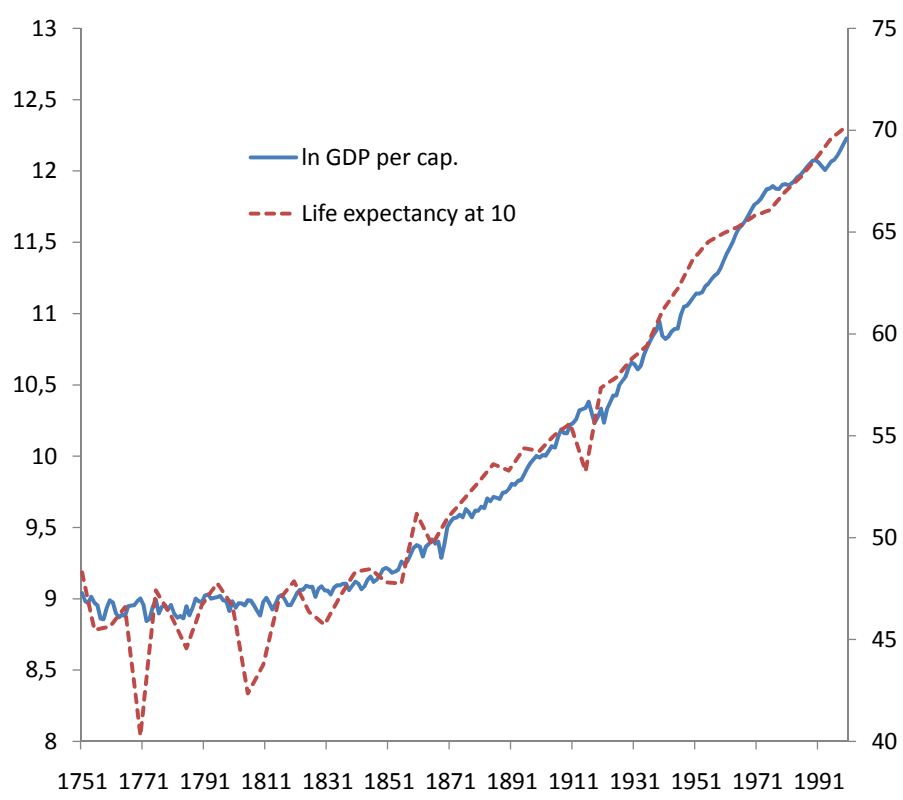

This positive relation between adult longevity and growth is also found is a cross-section of countries. Figure 2 plot this relationship for the year 2000. Life expectancy at age 10 is taken from the life tables provided by the World Health Organization (and results

\footnotetext{
${ }^{1}$ Already in 1749 , Sweden established a public agency with a responsibility for producing population statistics. These statistics were based on population records kept by the parish priests of the Swedish Lutheran church. Thanks to this effort we have access to detailed data of high quality on how mortality and fertility changed as Sweden developed from a poor agricultural country in the 18th century into a rich, highly industrialized country in the 20th century (Hofsten and Lundström 1976).

${ }^{2}$ Historical estimates of GDP per capita in Sweden are available from several sources. Back to 1861 they all build on work done by Lindahl, Dahlgren, and Kock (1937) but lately these estimates have been extended backwards by Edvinsson (2005) all the way back to 1720 .
} 
from model life tables for certain countries), while GDP per capita is measured using the World Development Indicators. The relation between the two variables is also very strong; the countries lying much below the regression line are those which are strongly hit by the AIDS epidemics.

Figure 2: Life expectancy at age 10 and income per capita across countries (year 2000)

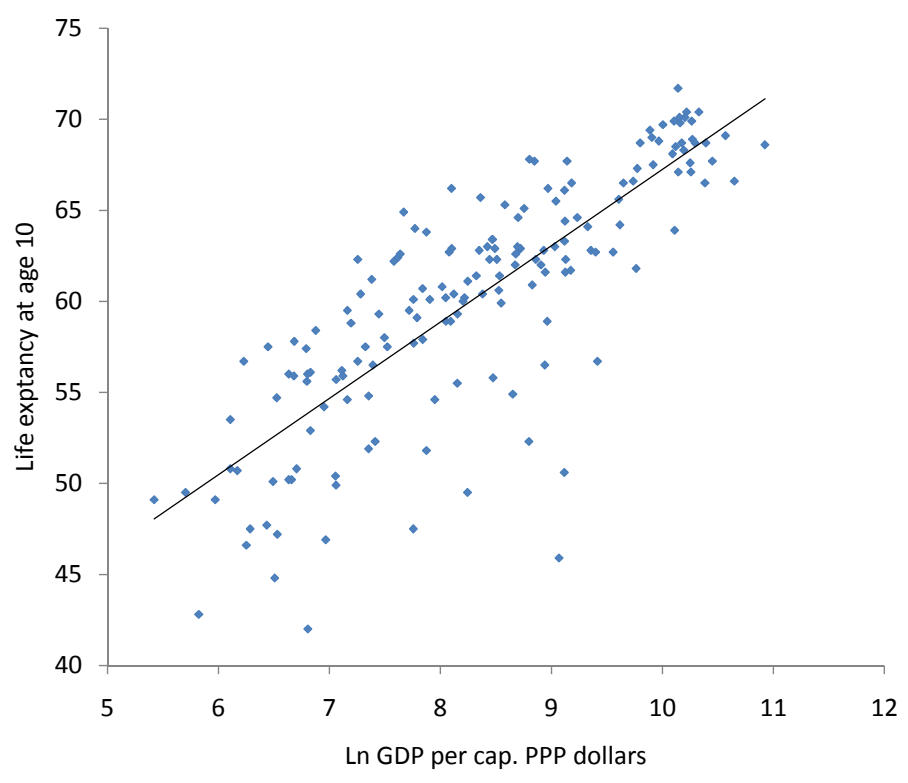

This strong relationship is obviously very important to understand the processes that led the various countries through the transition from stagnation to sustained growth (industrial revolution), but is also key to improve the design of today's development policy. Unfortunately, the correlations highlighted above do not say anything on the direction of causality. Did improvements in longevity simply follow better living conditions, and, at best, reinforced the growth process, or, on the contrary, did adult longevity rise before the industrial revolution and played a crucial role in its release?

It is undisputed that longevity was positively influenced by standard of livings. However, the question on whether longevity played a key role in the industrial revolution is disputed. The two views mentioned above are present in the literature. The view according to which longevity improvements reinforce growth but were not key is illustrated by the following citation:

It appears that the industrial demand for human capital (...) provided the inducement for investment in education and the associated reduction in fertility rates, whereas the prolongation of life may have re-enforced and complemented this process. (Galor 2005)

The alternative according to which longevity played a key role was earlier defended by the same author: 
Changes in mortality can serve as the basis for a unified model that describes the complete transition from the Malthusian Regime to the Modern Growth Regime. Consider the effect of an initial reduction in mortality (due to an exogenous shock to health technology or to standards of living). The effect of lower mortality in raising the expected rate of return to human capital investments will nonetheless be present, leading to more schooling and eventually to a higher rate of technological progress. This will in turn raise income and further lower mortality...(Galor and Weil 1999)

In this paper we defend the idea that longevity is a key factor. For this purpose we will provide four arguments using various data sets: Geneva and Venice longevity data before the Industrial Revolution (Section 3), mortality data of English aristocrats (Section 4), evidence on the rise in medical knowledge (Section 5), and height of Swedish soldiers (Section 6). Before going into these details we briefly survey various theories which formally examine mechanisms through which longevity affects growth (Section 2).

\section{Theories}

Theories accounting for a positive effect of adult longevity on income per capita can be classified into four categories.

We label the first theory the Ben Porath mechanism, following Ben-Porath (1967)'s seminal contribution. According to this theory, the return to investment in education depends on the length of time during which education will be productive, i.e. a longer active life makes initial investment in human capital more profitable. Longer education makes future income higher. Provided that human capital is an engine of growth, this may in turn sustain permanent income growth. The first authors to put this argument at work in an endogenous growth model are de la Croix and Licandro (1999). Further contributions are in Boucekkine, de la Croix, and Licandro (2002), Soares (2005) and Cervellati and Sunde (2005). Quantifications of the effect can be found in de la Croix, Lindh, and Malmberg (2008) and Cordoba and Ripoll (2008).

A second mechanism argues that longer lives give stronger incentives to save and invest. Let us label this the life-cycle hypothesis. Following the intuition of the life-cycle hypothesis, Nicolini (2004) claim that the increase in adult life expectancy must have implied less farmer impatience and could have caused more investment in nitrogen stock and land fertility, the increase in agricultural land, and higher production per acre in 18th century England.

Beyond the "horizon" effect caused by longer lives, there might also be a healthiness

effect. Healthier children have an increased capacity to absorb human capital (Hazan and Zoabi 2006).

The last mechanism is based on the fact that, keeping given fertility and migration, lower mortality increases the size of the population. Increased population density foster the 
efficiency of the transmission of human capital (Lagerloef 2003). Increased population growth may also fasten the advancement of skill-biased technologies (Weisdorf 2004).

Beyond these theoretical approaches to the interaction between longevity trends and long-run income growth prospects, there is another tradition which has an agnostic view of the mechanisms actually in place; it is the demographic dividend literature which analyzes the empirical relationships between demographic variables and growth in income per capita in recent data (see Bloom and Williamson (1998)). In this line, de la Croix, Lindh, and Malmberg (2009) consider a demographically-based statistical growth model estimated on global post-war growth data to study whether it can account for the long-term growth process that can be observed in the Swedish data. The global model estimates show a drift in the most productive activity period with life expectancy. The peak productivity shifts from around 30 years of age when life expectancy is low to an age around 50 for actual life expectancies in developed and emerging economies. The model is used to backcast Swedish economic growth back to 1750 . The backcast shows that the statistical model can account not only for recent changes in per capita income but also for the long-term process of Swedish economic development since the mid 19th century.

\section{Geneva and Venice Data ${ }^{3}$}

To assess the role of the decline in mortality in the economic take-off of Western Europe, it is necessary to distinguish the fluctuations of infant mortality from the reduction in the mortality of adults. Infant mortality fluctuates strongly as a function of economic and sanitary conditions, as children will be the first to suffer from bad crops and diseases. Child mortality has a major influence on the estimation of life expectancy at birth. Since improvements in infant mortality have arisen very late in the nineteenth century, it is not surprising that life expectancy at birth shows little trend before that time. Using the data built by Wrigley and Schofield (1989) for England, life expectancy at birth peaks in England at 39.5 years around the year 1575, then drops to 33 years in the period 1670-1750, and rises again and reaches its 1575 level in 1820. Then, it remains steady at 40 years until 1850. However, this absence of large improvement before 1850, due to a high and volatile infant mortality, hides more subtle improvements on the front of adult mortality. We shall eliminate the effects of this volatility on life expectancy estimations to get a much better picture of the evolution of adult mortality.

To study how adult mortality evolved over time, we need cohort life tables at different periods. We have found two data sets adapted to our purposes. The first one is from Perrenoud (1978) who constructed life tables from 1625 to 1825 on the basis of a wide nominative study in Geneva (Switzerland). The second set is built by Beltrami (1951). He uses parish registers to reconstitute age-group dynamics of the Venetian population over the period 1600-1790. Complete life tables are available for the cohorts born between

\footnotetext{
${ }^{3}$ This section borrows some material from Boucekkine, de la Croix, and Licandro (2003).
} 
Figure 3: Survival probabilities - Geneva

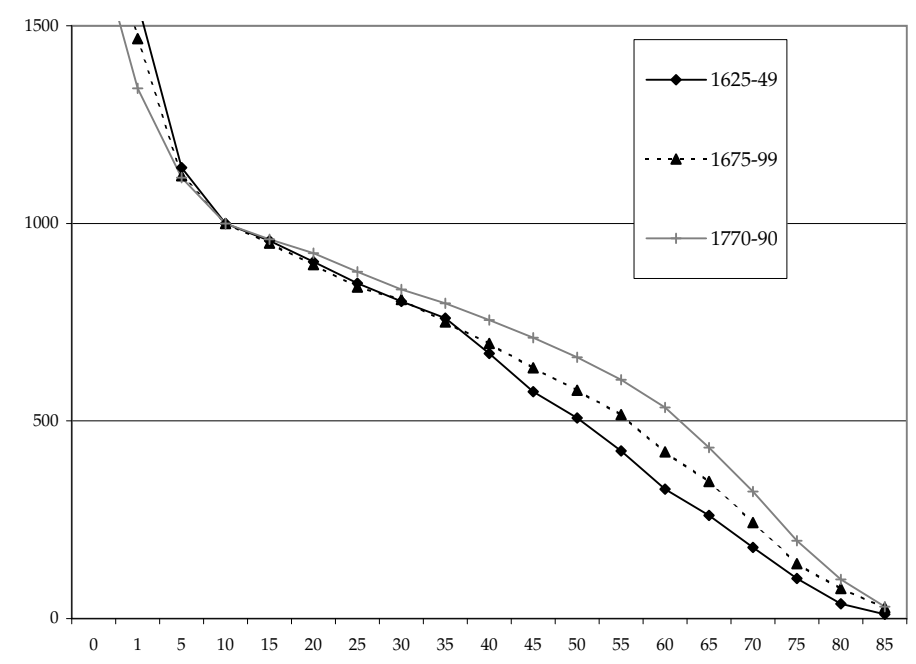

1600 and 1700; for the cohorts born after 1700 we only have partial tables, since the study ends in 1790. Survival laws are normalized to 1000 at age 10 . By doing so, we eliminate the shifts generated by changes in infant mortality and concentrate on the mortality of adults. Figures 3 and 4 display the survival laws of selected cohorts. These data sets are available from the author upon request.

The Geneva's picture, Figure 3, displays upward shifts of the curve from one generation to the next. The drop in the death rates essentially concerns the ages 40 to 65 . Notice that the end of the curve does not move much, reflecting that the gains in longevity do not translate into a rise in the maximum attainable age. Very few persons live longer than 85 .

In Figure 4 we find the same trend in Venice's data, that have been built from different sources. The lower curve represents the survival law for the generation born in 16001610. The dip in the curve at the age of 30 reflects the dramatic plague experienced by the city in 1630. The data from this period are thus rather pessimistic about longevity, as they take into account the damage caused by these particularly vigorous epidemics. To have a more prudent view of the improvement in longevity, we can compare the generation born in 1630-1640 to the one born in 1710-1720. There is no plague during this century in Venice (except the one of 1630 that only affects infant mortality of the generation 1630-40). Here again, the gains in longevity are concentrated on the working ages, and life expectancy at 10 increases significantly over the period.

The main finding of Boucekkine, de la Croix, and Licandro (2003) that the observed changes in adult mortality from the last quarter of the seventeenth century to the first quarter of the eighteenth century described in Figures 3 and 4 played a fundamental role in launching modern growth. The decline in adult mortality induced an increase in the growth rate of around $70 \%$ of the increase estimated by Maddison. This study thus 
Figure 4: Survival probabilities - Venice

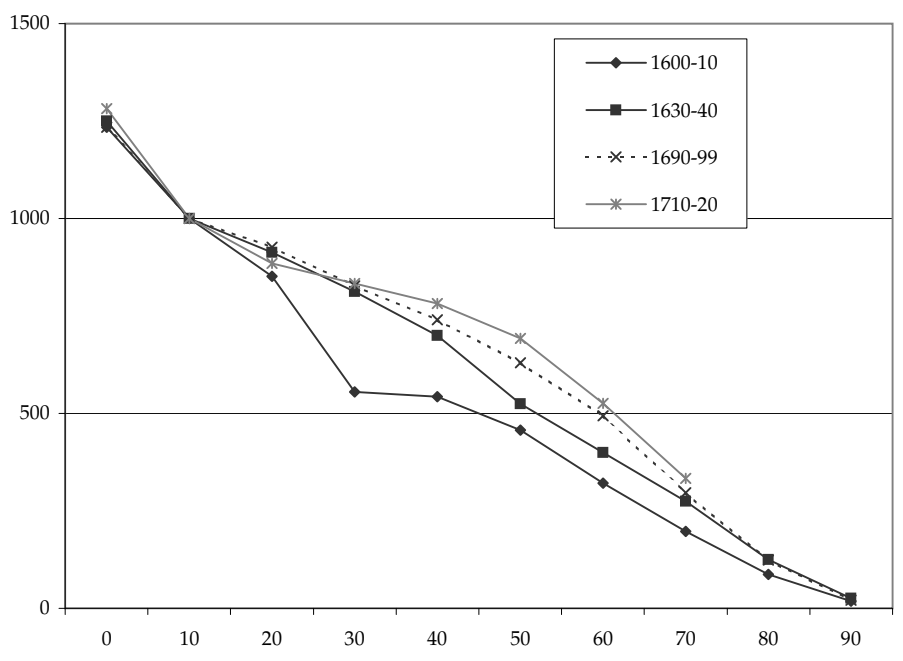

promotes the view that the early decline in adult mortality is responsible for a large part of the acceleration of growth at the dawn of the modern age.

The debate concerning the causes of the initial decline in mortality is not settled yet. The classical view is that pre-industrial mortality was reduced when nutritional standards were improved. Perrenoud (1985) and Fridlizius (1985) claim that human factors (nutrition, medicine, sanitary conditions and economy) did not play a prominent role in the first phase of the process. Instead, the decline in mortality should be found elsewhere; it can be connected to changes in immunology and/or improvement in the climate.

Could the shifts of the survival curve witnessed in Geneva and Venice be generalized to the whole Europe? We do not know, but at least not probably to England. In Boucekkine, de la Croix, and Peeters (2007), we estimate that mortality improvements account for only one sixth of the rise in literacy and growth in England over the period 1530-1860. This is small especially compared to the important role is was supposed to play in Nicolini (2004) and Boucekkine, de la Croix, and Licandro (2003).

Looking first at the raw data, Figure 5 compares the survival function in England as estimated by Wrigley et al. (1997) with the one for Geneva from Figure 3. Again we have normalized the series to 1000 at the age of 10 to concentrate on the mortality of adults. During the early seventeenth century (data for 1625-49), surviving was more likely in England than in Geneva, specially for the ages 35-65. English longevity was remarkably high for this period. Fifty years later, mortality in Geneva has dropped substantially, becoming lower compared to England. More surprisingly, English mortality has in fact increased over this period. This different evolution in mortality is probably due to the sharp rise in urbanization in England. At that time, big cities were unhealthy places. According to Bairoch, Batou, and Chèvre (1988), the population of London went from 
Figure 5: Estimated survival probabilities - England

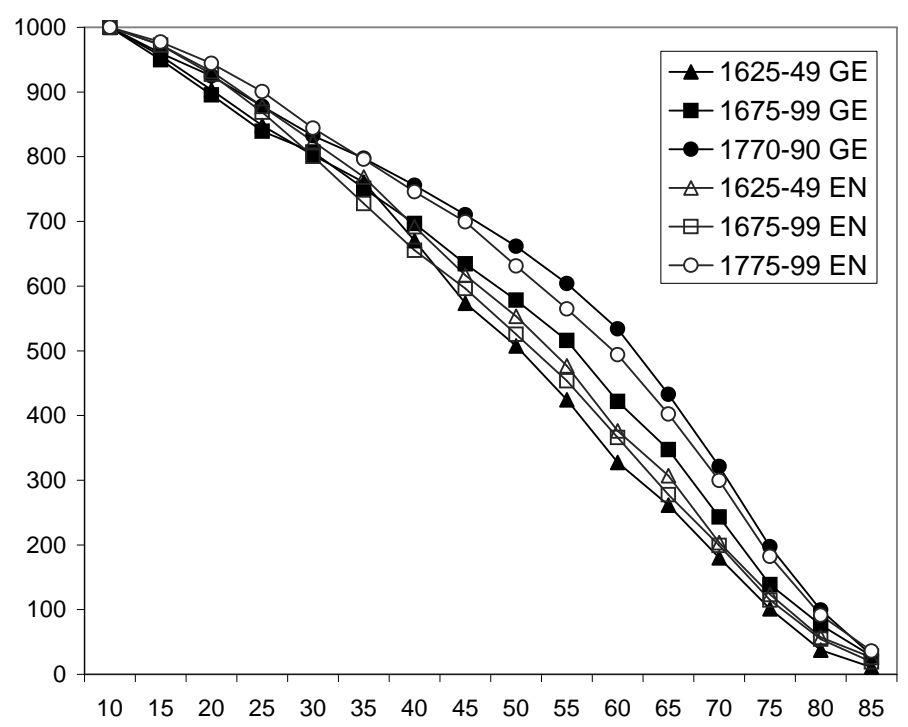

50 thousands in 1500 to 948 thousands in 1800, while it grew only from 12 thousands to 25 thousands in Geneva over the whole period. In the eighteenth century, finally, survival probabilities increased at all ages in both England and Geneva. Over the two centuries, the improvements in longevity were steady in Geneva, while they came quite late in England probably because of the fast urbanization process. This is why, in the quantitative exercise of Boucekkine, de la Croix, and Peeters (2007), mortality reductions play a role only in the eighteenth century.

\section{English Aristocrats ${ }^{4}$}

Another way to search for changes in mortality that could have preceded the Industrial Revolution is to look for forerunners in mortality decline. Even if little is visible at the aggregate level, longevity improvements benefiting specific groups could have sparked a modification in their behavior along the lines proposed in Section 2.

It is difficult to find data on mortality rates or life expectancy by income groups for the pre-industrial period. We gather here some evidence for England as a whole, combining sources from Hollingsworth (1977) and Wrigley et al. (1997), and for two cities in continental Europe, based on surveys by Perrenoud (1975) and Bardet (1983).

Starting with England, Figure 6 compares life expectancy at birth of the average person (from parish records (Wrigley et al. 1997)) with that of the English aristocracy (from genealogical data (Hollingsworth 1977)). Before 1700, there is not much difference in adult mortality across social classes. Surprisingly the elites have lower life expectancy;

\footnotetext{
${ }^{4}$ This section borrows some material from de la Croix and Sommacal (2009).
} 
Figure 6: Life expectancy at birth in England years

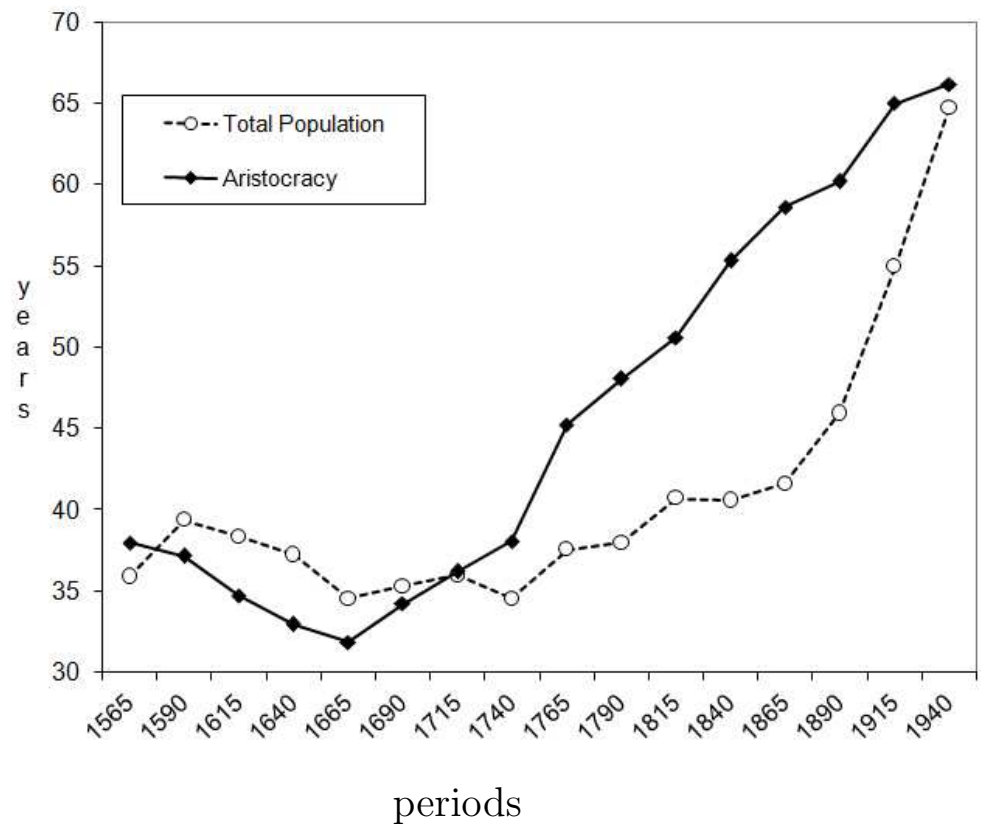

Table 1: Survival rates in Geneva and Rouen social Survival probabilities class $\quad 0 \rightarrow 15 \quad 15 \rightarrow 30 \quad 30 \rightarrow 45$

\begin{tabular}{lcccc} 
& class & $0 \rightarrow 15$ & $15 \rightarrow 30$ & $30 \rightarrow 45$ \\
\hline \multirow{2}{*}{ Geneva } & workers & 0.34 & 0.80 & 0.70 \\
XVII & merchants & 0.45 & 0.84 & 0.74 \\
& nobility & 0.61 & 0.89 & 0.81 \\
& & & & \\
Rouen & workers & 0.33 & 0.85 & 0.87 \\
XVIII & merchants & 0.49 & 0.87 & 0.86 \\
& nobility & 0.47 & 0.86 & 0.84 \\
\hline
\end{tabular}


this unexpected result is attributed by Johansson (1999) to an urban penalty paid by the aristocracy for the pleasures and opportunities of city life. The quasi-egalitarian mortality regime began to change by 1700 . Life expectancy rose for all groups but faster and further for the elite.

In de la Croix and Sommacal (2009) we argue that this picture could be consistent with a decomposition of the evolution of medical knowledge and life expectancy into three periods. Before the seventeenth century the effectiveness of medicine was very low. In fact, medicine was probably not effective at all. Given the low effectiveness of medical services, doctors hardly managed to increase the life expectancy of their patients. As a consequence, differential mortality between the rich (who could afford the services of a doctor) and the common people was very low, or even non-existent: income was of little importance in determining life expectancy. Next came a time when medicine became more effective. The rich were the first to benefit from these improvements, and their life expectancy rose. Differential mortality started to increase, because the improvements in longevity still did not benefit the whole population. In the third period there was a global improvement in health. Medicine became more and more effective, and the advantage of the upper classes in terms of longevity declined. Differential mortality decreased. We will look further into the evolution of medical knowledge over time in the next section.

Two other data sets can give further hints about mortality by social class before the Industrial Revolution. They cover the population of two cities in continental Europe, Geneva (Perrenoud 1975) and Rouen (Bardet 1983). Age-specific survival probabilities are presented in Table 1 for three social classes. In both data sets, infant mortality rates are much lower in the elite groups. This reflects their better living conditions. We also find that in Geneva (XVII century) and in Rouen (XVIII century) there was not much difference in adult mortality across social classes. In Rouen, there was no significant difference in the survival probabilities from age 15 to age 30 or from age 30 to age 45 of notables and simple workers. This is in line with the English data presented above. In Geneva, the upper social class had a slight advantage.

\section{$5 \quad$ Rise in Medical knowledge ${ }^{5}$}

We have seen in the previous sections that adult longevity started to improve before the increase in income per capita related to the Industrial Revolution. The determinants of the evolution of life expectancy during these centuries have been the subject of lively discussions in medical history and mortality history. One of the issue concerns the role of medical science. Remember Galor and Weil citation provided in the introduction: "Consider the effect of an initial reduction in mortality (due to an exogenous shock to health technology or to standards of living)..." We are precisely looking for this exogenous shock.

\footnotetext{
${ }^{5}$ This section borrows some material from de la Croix and Sommacal (2009).
} 
As a matter of medical knowledge, it is certain that ancient ideas persisted a long time in modern Europe and the confidence of consumers in medicine was low. Popular proverbs endorsed this distrust: one doctor makes work for another ${ }^{6}$. As a consequence some authors claim that the rise of life expectancy in early modern Europe relied more on changes in immunology and/or improvement in the climate than on human factors such as medical advances.

Johansson (1999) argues against the traditional therapeutic nihilism that tends to deny that medicine had any effectiveness before the end of the nineteenth century, and suggested an increase in medical effectiveness as a possible explanation for the change, documented in Figure 6, from an egalitarian mortality regime to a regime characterized by a mortality differential between rich and poor people.

Indeed in the period 1500-1800, medicine showed an increasingly experimental attitude: no improvement was effected on the grounds of the disease theory (which was still mainly based on traditional ideas), but significant advances were made based on practice and empirical observations. For example, although the theoretical understanding of how drugs work only came progressively in the nineteenth century with the development of chemistry (Weatherall 1996), the effectiveness of the treatment of some important diseases was improved thanks to the practical use of new drugs coming from the New World. ${ }^{7}$ Advances in the treatment of Syphilis were made due to improvements in the development of condoms. For a long period, mainly due to their high cost, these new medical advances were only available to rich people ${ }^{8}$.

Moreover Table 2, which shows the number of books containing lifestyle advice written in the period 1600-1800 by sub-periods, provides some indirect evidence of the fact that lifestyle advice (concerning, for example, personal and domestic cleanliness) became popular among upper class readers. This trend is also supported by the evidence provided by Baten and van Zanden (2008) on book production in early modern Europe from 1450 to 1799 .

As suggested by Johansson (1999) the cumulative effects of these improvements could have produced a net increase in the efficacy of medicine in the eighteenth century. "As early as 1829 Dr.F.B. Hawkins wrote a book entitled Elements of Medical Statistics, in which lie described what could be called an early modern epidemiological transition. Several centuries before his own time leprosy, plague, sweating sickness, ague, typhus, smallpox, syphilis and scurvy had been leading causes of death. Now all of these diseases

\footnotetext{
${ }^{6}$ For further details of the history of medicine: Siraisi (1990) and Porter (1995).

${ }^{7}$ Ipecacuanha was used for severe dysentery, guaiacum for syphilis, and the bark of the cinchona tree for malaria. Citrus fruits started to be used in the prevention and treatment of scurvy.

${ }^{8}$ In the eighteenth century bubonic plague also disappeared from England. The reasons for this are still hotly debated and some authors explain it in exogenous terms. In any case, independently of this debate, it should be noticed that by the seventeenth century a "warning system" had been developed in London. Weekly bills of mortality, containing the cause of death, were published: when the number of plague deaths reached a worrying value, foreshadowing the outbreak of an epidemic, people with enough money to move left the city. This system, though not effective in the treatment of the plague itself, can be interpreted as a public health measure, that had an effect on the health of rich people.
} 
had disappeared, could be cured, or treated effectively. At the present scarlet fever, consumption, gout, dropsy, palsy, apoplexy (including heart attacks and strokes), mania, and diseases of the brain were the most prevalent causes of death. The last six of the eight diseases listed were not contagious; they were chronic diseases most likely to strike older adults" (Johansson 1999, p. 48).

Table 2: Number of books on health published in England, 1600-1800

\begin{tabular}{cc} 
Period & Number of books \\
\hline $1600-24$ & 9 \\
$1625-49$ & 16 \\
$1650-74$ & 17 \\
$1675-99$ & 25 \\
$1700-24$ & 28 \\
$1725-49$ & 34 \\
$1750-74$ & 53 \\
$1775-1800$ & 81 \\
\hline
\end{tabular}

We conclude this section with an important remark. Even if advances in medical knowledge and practice (as above, we use this term in a broad sense, to include lifestyle advice) could be responsible for early improvements in the length of life, this does not mean that the increase in life expectancy can be explained only by advances in medical science. Many factors may have contributed to the reduction in mortality since the eighteenth century (nutrition, medicine, immunology, etc.) and attributing a specific weight to each of them is very difficult (Fogel 2004). Medical effectiveness could still be key to explain the differential mortality between social classes before the Industrial Revolution.

\section{$6 \quad$ Height of Swedish Soldiers ${ }^{9}$}

Let us now go deeper into one mechanism through which adult longevity could have increased. From the epidemiology literature we know that providing children with appropriate health care and nutrition and promoting good attitudes towards health ensure them a longer life when adults (see a survey in Harris (2001)). Starting with Kermack, McKendrick, and McKinlay (1934), who showed that the first fifteen years of life were central in determining the longevity of the adult, the relationship between early development and late mortality within cohorts has been well-established. Another important contribution in the field is that of Barker and Osmond (1986) who related lower childhood health status to higher incidence of heart disease in later life. This idea also had an echo in the literary tradition as witnessed by the aphorism "The Child is Father of

\footnotetext{
${ }^{9}$ This section borrows some material from de la Croix and Licandro (2007).
} 
the Man" (Wordsworth 1802), meaning that the way a child is brought up determines what he or she will become in the future.

Height is a simple measure of childhood development, since both better nutrition and lower exposure to infections leads to increased height. ${ }^{10}$ Height is constant after, say, the age of 18 , but is still a good predictor of life expectancy and mortality in old age. According to Waaler (1984), the trend towards greater height found in the data means that younger cohorts, which have grown up with better nutrition, will have better health and live longer as adults.

Height is a frequently used indicator in microeconomic studies of the relationship between health and income. Weil (2007) finds that the effect on wages of an additional centimeter of height ranges between $3.3 \%$ and $9.4 \%$, depending on the data set used. In a second step, he exploits the correlation between height and direct measures of health such as the adult survival rate to evaluate health's role in accounting for income differences among countries; he finds that eliminating health variations would reduce world income variance by a third.

The height of conscripts has been systematically recorded by the Swedish army since 1820, which provides time-series information on changes in height throughout the demographic transition. Figure 7 presents data ${ }^{11}$ for the cohorts born between 1760 and 1960. The left panel shows that the height of soldiers (measured at approximately age 20 ) is highly correlated with the life expectancy of the same generation. ${ }^{12}$ The right panel of Figure 7 shows that body height and years of schooling are positively correlated and, more importantly, that changes in height precede changes in education.

In de la Croix and Licandro (2007) we propose a new theory of the demographic transition based on the evidence reported above that body development during childhood is an important predictor of life expectancy. The key and novel mechanism we propose is that parents face a trade-off between the quantity of children they have and the amount they can afford to spend on each of them during childhood. Parents like to have children, but they also care about their longevity. By ensuring an appropriate physical development for their children and protecting them from infections, parents provide them with greater health capital and a longer life. Such provision is costly though, and its cost is proportional to the number of children. As a consequence, having many children prevents parents of spending much on their health capital. The proposed quality/quantity trade-off makes longevity and fertility negatively related.

\footnotetext{
${ }^{10}$ According to Silventoinen (2003), height is a good indicator of childhood living conditions (mostly family background), not only in developing countries but also in modern Western societies. In poor societies, the proportion of cross-sectional variation in body height explained by living conditions is larger than in developed countries, with lower heritability of height as well as larger socioeconomic differences in height.

${ }^{11}$ Sources: Sandberg and Steckel (1997) for height data from 1820; Floud (1984) for height data before 1820 from Denmark); The "Human Mortality Database" for life expectancy data; and de la Croix, Lindh, and Malmberg (2008) for education data.

${ }^{12}$ Notice that this strong correlation over time can also be established in a cross section of countries: Baten and Komlos (1998) regressed life expectancy at birth on adult height and explained $68 \%$ of the variance for a sample of 17 countries in 1860.
} 
Figure 7: Height, Life Expectancy and Education in Sweden

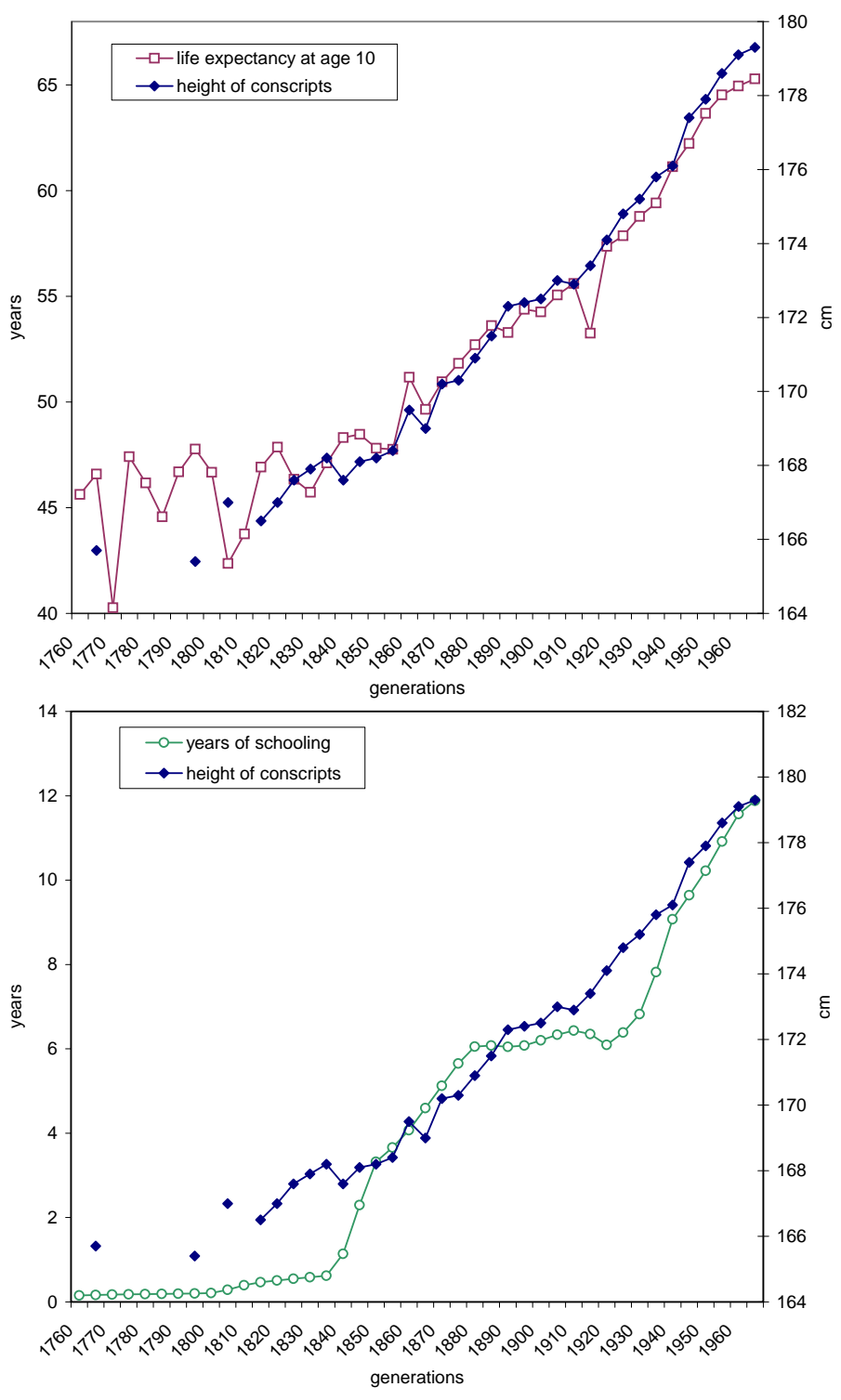


In our paper, the mechanism relating demographics and growth is the Ben-Porath hypothesis that longevity positively affects education and human capital accumulation, by extending an individual active life. We assume that adults decide about their own optimal amount of education, and we take basic education, even if provided by parents, as being exogenously given. In addition to the trade-off between the number and development of children stressed above, adults face a trade-off between having children and improving their own education, which makes the number of children and schooling negatively related. This is similar to the trade-off faced by parents in a Beckerian world, where they care about the quantity and quality (education) of their offsprings.

The dynamics of de la Croix and Licandro (2007)'s model displays the key features of the demographic transition, including the hump in total net fertility rate and in population growth. In particular, it is able to replicate the observed rise in life expectancy and educational attainment, as well as the initial increase and then decline in fertility. If the mechanisms we describe predominate, the logic of the demographic transition could well be the reverse of that which is usually assumed: the key trade-off is not between fertility and education, with effects on longevity as a byproduct, but between fertility and healthier and longer living children, with a subsequent effect on education. This timing is evident in the data presented above.

\section{Concluding Remark}

The transition from a world of low economic growth with high mortality and high fertility to one with low mortality and fertility but sustained growth has been the subject of intensive research in recent years. In this literature, the relation between growth and fertility results from the quantity/quality trade-off faced by parents between the number of children and their education. Indeed, the gradual increase in the observed level of for human capital during the nineteenth century 'has led researchers to argue that the increasing role of human capital in the production process induced households to increase investment in the human capital of their offspring, ultimately leading to the onset of the demographic transition' (Galor 2005). If the rise is education was indeed driven by a stronger demand for skills from the industrial sector, one should have observed a rise in the skill premium during and following the industrial revolution.

Looking for such evidence, Clark (2005) computes a skill premium over the period 12201990 in two different ways. First by measuring the relative wage of all skilled building workers relative to all laborers and, second, by using only those observations in which there is a matched pair for the same place and year of wages for craftsmen and laborers. The two methods lead to the same conclusion: the skill premium did not rise during the Industrial Revolution. And Clark concludes that 'The market premium for skills, does not explain the increased investment in human skills evident after 1600.' Hence, we

might wonder whether the human capital interpretations of the Industrial Revolution are based on the right trade-off. 
The evidence provided in this paper points to an alternative mechanism which does not require any increase in the skill premium (and hence would not be dismissed by Clark's data) because it is based on a supply side argument. Rather than grounding the rise in education on the growing demand for skilled workers from the industry, we argue that households may have wanted to increase their investment in human skills as a response to longer lives.

The whole story line could then be as evoked by Galor and Weil (1999): following a positive shock to health technology, the environment during childhood improved and adult mortality consequently decreased. This occurred at least for a sub-group of the population: the upper class, and those living in cities. This raised the expected rate of return to human capital investments for them, leading to more education, a faster accumulation of skills, and eventually to a higher rate of productivity growth. This in turn initiated the transition from Malthusian stagnation to sustained growth.

\section{References}

Bairoch, Paul, Jean Batou, and Pierre Chèvre. 1988. The population of European Cities from 800 to 1850. Genève: CIEH.

Bardet, Jean-Pierre. 1983. Rouen au XVII et XVIII siècles. Edited by SEDES. Paris.

Barker, David, and Clive Osmond. 1986. "Infant mortality, childhood nutrition, and ischaemic heart disease in England and Wales." Lancet i:1077-1088.

Baten, Joerg, and John Komlos. 1998. "Review: Height and the Standard of Living." The Journal of Economic History 58 (3): 866-870.

Baten, Joerg, and Jan Luiten van Zanden. 2008. "Book production and the onset of modern economic growth." Journal of Economic Growth, p. forthcoming.

Beltrami, D. 1951. "Lineamenti di storia della popolazione di Venezia nei secoli XVI, XVII e XVIII." Atti dell'Istituto Veneto di Scienze, Lettere ed Arti, vol. 109.

Ben-Porath, Yoram. 1967. "The production of human capital and the life-cycle of earnings." Journal of Political Economy 75 (4): 352-365.

Bloom, David E., and Jeffrey G. Williamson. 1998. "Demographic Transitions and Economic Miracles in Emerging Asia." World Bank Economic Review 12 (3): 419455 (September).

Boucekkine, Raouf, David de la Croix, and Omar Licandro. 2002. "Vintage human capital, demographic trends and endogenous growth." Journal of Economic Theory 104:340-375.

- 2003. "Early mortality declines at the dawn of modern growth." Scandinavian Journal of Economics 105 (3): 401-418.

Boucekkine, Raouf, David de la Croix, and Dominique Peeters. 2007. "Early Literacy Achievements, Population Density, and the Transition to Modern Growth." Journal of the European Economic Association 5 (1): 183-226 (03). 
Cervellati, Matteo, and Uwe Sunde. 2005. "Human Capital Formation, Life Expectancy and the Process of Development." American Economic Review 95 (5): 1653-1672.

Clark, Gregory. 2005. "The Condition of the Working Class in England, 1209-2004." Journal of Political Economy 113 (6): 1307-1340.

Cordoba, Juan Carlos, and Mar Ripoll. 2008. "Life Expectancy and The Wealth of Nations." paper presented at SED 2008, Boston.

de la Croix, David, and Omar Licandro. 1999. "Life expectancy and endogenous growth." Economics Letters 65 (2): 255-263.

—. 2007. "The Child is Father of the Man: Implications for the Demographic Transition." Discussion paper 6493, CEPR.

de la Croix, David, Thomas Lindh, and Bo Malmberg. 2008. "Swedish Economic Growth and Education Since 1800." Canadian Journal of Economics 41:166-185.

- 2009. "Demographic change and economic growth in Sweden: 17502050." Journal of Macroeconomics, p. forthcoming.

de la Croix, David, and Alessandro Sommacal. 2009. "A Theory of Medical Effectiveness, Differential Mortality, Income Inequality and Growth for Pre-Industrial England." Mathematical Population Studies, p. forthcoming.

Edvinsson, Rodney. 2005. Growth, Accumulation, Crisis. Volume 41 of Stockholm Studies in Economic History. Stockholm: Almqvist \& Wiksell International. PhD thesis.

Floud, Roderick. 1984, April. "The Heights of Europeans Since 1750: A New Source For European Economic History." Working paper 1318, National Bureau of Economic Research, Inc.

Fogel, Robert. 2004. The Escape from Hunger and Premature Death, 1700-2100. Cambridge: Cambridge University Press.

Fridlizius, Gunnar. 1985. "The mortalty decline in the first phase of the demographic transition: Swedish experiences." In Pre-industrial population change, edited by Tommy Bengtsson, Gunnar Fridlizius, and Rolf Ohlsson, 71-114. Stockholm: Almquist and Wiksell International.

Galor, Oded. 2005. "From Stagnation to Growth: Unified Growth Theory." Chapter 4 of Handbook of Economic Growth, edited by Philippe Aghion and Steven Durlauf, Volume 1 of Handbook of Economic Growth, 171-293. Elsevier.

Galor, Oded, and David Weil. 1999. "From Malthusian stagnation to modern growth." American Economic Review 89 (2): 150-154.

Harris, Bernard. 2001. "'The child is father of man.' The relationship between child health and adult mortality in the 19th and 20th centuries." International Journal of Epidemiology 30:688-696.

Hazan, Moshe, and Hosny Zoabi. 2006. "Does longevity cause growth? A theoretical critique." Journal of Economic Growth 11:363-376. 
Hofsten, Erland, and Hans Lundström. 1976. Swedish population history: main trends from 1750 to 1970. Stockholm: LiberFörlag.

Hollingsworth, Thomas. 1977. "Mortality in the British peerage families since 1600." Population 32:323-352.

Johansson, Ryan. 1999. "Death and the doctors: medicine and elite mortality in Britain from 1500 to 1800." Cambridge Group for the History of Population and Social Structure Working Paper Series. No. 7.

Kermack, William, Anderson McKendrick, and P McKinlay. 1934. "Death Rates in Great Britain and Sweden: some general regularities and their significance." Lancet i:698-703.

Lagerloef, Nils-Petter. 2003. "From Malthus to modern growth: can epidemics explain the three regimes ?" International Economic Review 44 (2): 755-777.

Lindahl, Erik, Einar Dahlgren, and Karin Kock. 1937. National Income of Sweden 1861-1930, Part One and Two. Volume III of Wages, Cost of Living and National Income of Sweden, 1860-1930. London: P.S. King \& Son, Ltd.

Nicolini, Esteban. 2004. "Mortality, interest rates, investment, and agricultural production in 18th century England." Explorations in Economic History 41 (2): 130-155.

Perrenoud, Alfred. 1975. "L'inégalité sociale devant la mort à Genève au XVII ${ }^{e}$ si'ecle." Population 30:221-243.

—. 1978. "La mortalité à Genève de 1625 à 1825." Annales de démographie historique, pp. 209-233.

- 1985. "Mortalty decline in its secular setting." In Pre-industrial population change, edited by Tommy Bengtsson, Gunnar Fridlizius, and Rolf Ohlsson, 41-69. Stockholm: Almquist and Wiksell International.

Porter, Roy. 1995. Disease, medicine, and society in England, 1550-1860. New Studies in Economic and Social History. Cambridge: Cambridge University Press.

Sandberg, Lars, and Richard Steckel. 1997. "Was Industrialization Hazardous to your Health? Not in Sweden." In Health and Welfare during Industrialization, edited by Richard Steckel and Roderick Floud. University of Chicago Press.

Silventoinen, Karri. 2003. "Determinants of Variation in Adult Body Height." Journal of Biosocial Science 35:263-285.

Siraisi, Nancy. 1990. Medieval and Early Renaissance Medicine: An Introduction to Knowledge and Practice. Chicago: University of Chicago Press.

Soares, Rodrigo R. 2005. "Mortality Reductions, Educational Attainment, and Fertility Choice." American Economic Review 95 (3): 580-601 (June).

Waaler, Hans. 1984. "Height, weight and mortality: the Norwegian experience." Acta medica Scandinavica. Supplementum 679:1-56.

Weatherall, Miles. 1996. "Drug treatment and the rise of pharmacology." In Cambridge Illustrated History: Medicine. Cambridge: Cambridge University Press. 
Weil, David. 2007. "Accounting for the Effect of Health on Economic Growth." Quarterly Journal of Economics, p. forthcoming.

Weisdorf, Jacob L. 2004. "From stagnation to growth: Revisiting three historical regimes." Journal of Population Economics 17 (3): 455-472 (08).

Wordsworth, William. 1802. My heart leaps up when I behold. Poem.

Wrigley, Edward, Ros Davies, James Oeppen, and Roger Schofield. 1997. English Population History from Family Reconstitution: 1580-1837. Cambridge: Cambridge University Press.

Wrigley, Edward, and Roger Schofield. 1989. The population history of England, 15411871: a reconstruction. Cambridge, Mass: Cambridge University Press. 
Département des Sciences Économiques de l'Université catholique de Louvain

Institut de Recherches Économiques et Sociales

Place Montesquieu, 3

1348 Louvain-la-Neuve, Belgique 